\title{
Dual Oxidase Maturation factor 1 (DUOXA1) overexpression increases reactive oxygen species production and inhibits murine muscle satellite cell differentiation
}

Shelley DE Sandiford ${ }^{1 *}$, Karen AM Kennedy ${ }^{2}$, Xiaojun Xie ${ }^{2}$, J Geoffrey Pickering ${ }^{2}$ and Shawn SC Li ${ }^{1 *}$

\begin{abstract}
Background: Dual oxidase maturation factor 1 (DUOXA1) has been associated with the maturation of the reactive oxygen species (ROS) producing enzyme, dual oxidase 1 (DUOX1) in the adult thyroid. However, ROS have also been implicated in the development of several tissues. We found that activated muscle satellite cells and primary myoblasts isolated from mice express robust levels of DUOXA1 and that its levels are altered as cells differentiate.

Results: To determine whether DUOXA1 levels affect muscle differentiation, we used an adenoviral construct (pCMV5-DUOXA1-GFP) to drive constitutive overexpression of this protein in primary myoblasts. High levels of DUOXA1 throughout myogenesis resulted in enhanced $\mathrm{H}_{2} \mathrm{O}_{2}$ production, fusion defects, reduced expression of early (myogenin) and late (myosin heavy chain) markers of differentiation, and elevated levels of apoptosis compared to control cells infected with an empty adenoviral vector (pCMV5-GFP). DUOXA1 knockdown (using a DUOXA1 shRNA construct) resulted in enhanced differentiation compared to cells subjected to a control shRNA, and subjecting DUOXA1 overexpressing cells to siRNAs targeting DUOX1 or apoptosis signal-regulating kinase 1 (ASK1) rescued the phenotype.
\end{abstract}

Conclusions: This study represents the first to demonstrate the importance of DUOXA1 in skeletal muscle myoblasts and that DUOXA1 overexpression in muscle stem cells induces apoptosis and inhibits differentiation through DUOX1 and ASK1.

Keywords: Muscle satellite cell, Stem cell, Myogenesis, Reactive oxygen species

\section{Background}

The process of myogenesis is often studied using activated satellite cells. These muscle stem cells, located between the plasma membrane and the basal lamina, form the basis for effective muscle regeneration [1]. Under appropriate stimuli, these normally quiescent cells enter back into the cell cycle, and undergo several rounds of proliferation. Myoblast progression towards mature muscle is initiated by permanent cell cycle exit. These cells, now called myocytes, line up and fuse with neighboring cells to produce a single-membrane structure

\footnotetext{
* Correspondence: sdsandiford@gmail.com; sli@uwo.ca

${ }^{1}$ Siebens-Drake Research Institute, 1400 Western Road, London, Ontario N6G 2 V4, Canada

Full list of author information is available at the end of the article
}

housing potentially hundreds of nuclei. The process of myogenesis is dependent upon the expression of the Myogenic Regulatory Fators (MRFs) that include Myf5, MyoD, myogenin and MRF4 [2]. Both MyoD and Myf5 are expressed in proliferative myoblasts and Myf5 is downregulated as cells progress through myogenesis. Once the cells exit the cell cycle, myogenin and MRF4 are expressed. MRF4 can also act upstream of Myf5 and MyoD [3].

Although there appears to be a certain degree of redundancy between the MRFs, data from knockout studies suggest unique roles for these transcription factors. The majority of myoblasts follow this rather predictable pattern of myogenesis and, in mature muscle, most of the nuclei are terminally differentiated. However, the

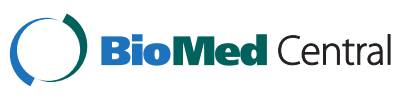


process of myogenesis is also characterized by a small percentage of cells that escape differentiation, maintain Pax7 expression, downregulate $\mathrm{MyoD}$, and return to quiescence [4]. These $\mathrm{Pax}^{+} / \mathrm{MyoD}^{-}$cells are thought to maintain a small pool of muscle stem cells, from which future proliferative myoblasts may be derived. Cells that escape differentiation and that fail to return to quiescence undergo apoptosis [5,6]. Indeed, apoptosis is normally regarded as a natural part of differentiation, and identifying factors involved in cell cycle control and survival undoubtedly play an important role in our general understanding of myogenesis and in the etiology of many muscle degenerative diseases.

Previously, our lab characterized a protein termed Numb Interacting Protein (NIP), an interactor of the cell fate determinant, Numb, in Drosophila Melanogastor [7]. Mammals have two isoforms of NIP (NIP1 and NIP2), but the role of mammalian NIP genes in Numb function has not been demonstrated. Subsequently, others identified NIP1 and NIP2 as genes arranged in head-to-head orientation with dual oxidases (DUOX1 and DUOX2) [8]. Specifically, the protein products of these genes, renamed DUOXA1 and DUOXA2 respectively, were shown to be important for the maturation of DUOX1 and DUOX2 and, ultimately, the production of $\mathrm{H}_{2} \mathrm{O}_{2}$ and thyroid hormone. Dual oxidases belong to the nicotinamide adenine dinucleotide phosphate (NADPH) oxidase (Nox) family of enzymes responsible for the generation of reactive oxygen species (ROS) in a variety of cell types [9-12]. The family is made up of Nox1 through Nox5 and DUOX1 and DUOX2. While some family members require additional subunits $\left(\mathrm{p} 47^{\text {phox }}\right.$ and $\mathrm{p} 67^{\mathrm{phox}}$ ) for proper function, DUOX1 and DUOX2 have no such requirement $[13,14]$. Instead, these two $\mathrm{Ca}^{2+}$-dependent Nox members rely on DUOXA1 and DUOXA2 for their maturation and/or translocation to the plasma membrane for their activation. Research has demonstrated that DUOXA1 and DUOXA2 form heterodimeric complexes with their respective dual oxidases $[15,16]$ and, in their absence, DUOX enzymes remain internalized in the endoplasmic reticulum and $\mathrm{H}_{2} \mathrm{O}_{2}$ is not produced. Interestingly, relatively few adult tissues have been demonstrated to express DUOXA1. Grasberger and Refetoff [8] confirmed high levels of this protein in a limited number of tissues including the thyroid, lung and salivary glands. Indeed, most of the studies on DUOXA1 and DUOXA2 revolve around their function in the thyroid and hormone biosynthesis and, not surprisingly, natural mutations in the DUOXA2 gene have been linked to hypothyroidism $[17,18]$. However, the presence of DUOX and DUOXA in primitive organisms (lacking a thyroid gland), suggests roles that extend beyond thyroid hormone biosynthesis [19]. Others have suggested that DUOX1 in lung epithelia may play a role in host defence [20], and silencing of DUOX1, DUOX2 and their respective maturation factors has been demonstrated in lung cancer cells [21]. Since 2006, DUOXA1 has been studied extensively as a mediator of DUOX1 activity. However, studies into the potential roles for DUOXA1 in other tissues and during development are lacking.

We have determined that DUOXA1 mRNA levels are altered throughout embryogenesis and that levels are elevated as early as embryonic (E) day seven (E7) in the developing mouse [22]. The early expression pattern of DUOXA1 (before the development of many organs) suggests that it may play important roles in embryogenesis. Here we report, for the first time, that DUOXA1 (and its corresponding dual oxidase, DUOX1) is expressed in murine muscle satellite cells and throughout myogenesis. Overexpression of DUOXA1 is associated with elevated levels of $\mathrm{H}_{2} \mathrm{O}_{2}$ and inhibition of differentiation through increased apoptosis in a DUOX1-dependent manner. We further show that a common regulator of apoptosis, apoptosis signal-regulating kinase 1 (ASK1), is a downstream target of DUOXA1-mediated $\mathrm{H}_{2} \mathrm{O}_{2}$ production, and that knockdown of either DUOX1 or ASK1 rescues the DUOXA1 overexpression phenotype.

\section{Results}

\section{Newly activated satellite cells and primary myoblasts} express DUOXA1

To determine whether muscle satellite cells express DUOXA1, myofibre cultures derived from mouse extensor digitorum muscle were examined by immunofluorescent microscopy. Robust DUOXA1 expression was detected at $24 \mathrm{hrs}$ of culture in cells that had entered back into the cell cycle (as demonstrated by positive BrdU staining (Figure 1A). In order to characterize the function of DUOXA1, we generated an anti-DUOXA1 antibody against the C-terminal portion of the mouse DUOXA1 protein. The specificity of the antibody was verified by overexpressing full length DUOXA1 in 293T cells, and by immunostaining performed on primary myoblasts in the absence or presence of the antigenic peptide (Additional file 1: Figure S1A-D). The antibody was also verified using the immortalized $\mathrm{C} 2 \mathrm{C} 12$ myoblast cell line (Additional file 1: Figure S1E).

We were also interested in knowing whether DUOXA1 expression was maintained in primary myoblasts that had migrated from the parent fibre. Primary myoblasts were derived from myofibre cultures, and culture purity was determined to be $>95 \%$ using the myoblast marker, desmin (data not shown). Immunostaining performed on proliferative myoblast $(\mathrm{MB})$ and differentiated myotube (MT) samples suggest that DUOXA1 is present in the nucleus and 


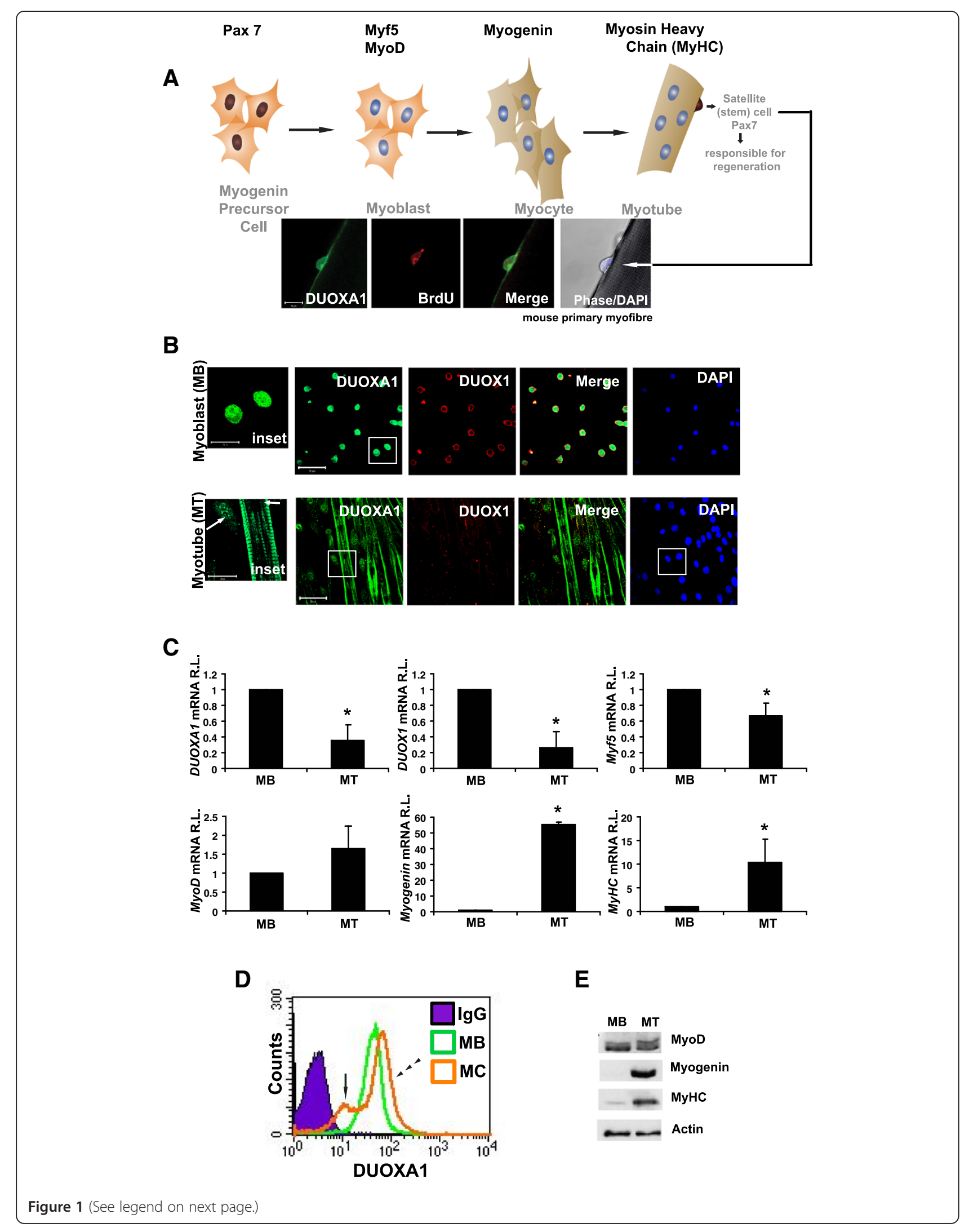




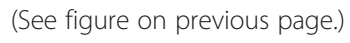

Figure 1 Newly activated satellite cells and primary myoblasts express DUOXA1. (A) Scheme of myogenesis indicating common markers for precursor cells (Pax7), myoblast commitment (Myf5, MyoD), early differentiation (myogenin) and late differentiation (Myosin heavy chain - MyHC). Myofibres were isolated and incubated with $10 \mu \mathrm{M}$ bromodeoxyuridine (BrdU). Samples were cultured for 24 hours, upon which time they were harvested, fixed in 2\% paraformaldehyde, and immunostained for DUOXA1 (green) and BrdU (red). Results show evidence of activated DUOXA1 ${ }^{+} / \mathrm{BrdU}^{+}$satellite cells. Scale bar: 20 m. (B) Myofibre and primary myoblast cultures obtained from the extensor digitorum longus muscles of adult mice demonstrate DUOXA1 expression in newly-activated satellite cells, primary myoblasts and differentiated myotubes. Primary myoblasts which have migrated away from the parent fibre also show extensive cytoplasmic and nuclear staining of DUOXA1 (green) in cells that co-express DUOX1 (red). The nuclei of differentiated myotubes are generally devoid of DUOXA1. White arrows indicate alterations in the localization of DUOXA1 in single cells compared to that in fused myotubes. Counterstaining with DAPI is provided as a nuclear marker. Scale bars: $50 \mu \mathrm{m}$. Inset scale bars: $20 \mu \mathrm{m}$. (C) The expression of DUOXA1 and DUOX1 (along with Myf5, MyoD, myogenin \& MyHC) in myoblast (MB) and myotube (MT) samples was analyzed by quantitative reverse transcription (qRT)-PCR. The levels of mRNA were normalized to GAPDH and presented as values relative to expression at day 0 (d0). (D) DUOXA1 levels in MB and myocyte samples (MC - which had not undergone fusion) were also analyzed by flow cytometry. The normal arrow and broken arrow heads in MC samples indicate populations of cells that have either downregulated or upregulated DUOXA1 expression respectively. (E) Markers of myogenesis were also analyzed by Western blot. * Significantly different from d0 (P $<0.05)$. mRNA R.L. indicates mRNA relative level.

cytoplasm of dividing myoblasts, and restricted to the cytoplasm of fused myotubes (Figure 1B).

\section{Dynamic DUOXA1 expression during myogenesis}

We next examined the temporal expression pattern of DUOXA1 as cells undergo differentiation. Proliferative primary myoblasts were either maintained in growth medium (GM), or allowed to differentiate for four days in differentiation medium (DM). Quantitative reverse transcription (qRT)-PCR suggests that DUOXA1 mRNA levels are altered as cells differentiate (Figure $1 \mathrm{C}$ and E). Due to differences in DUOXA1 localization between proliferating and differentiating cells, we decided to use flow cytometry as a means of further characterization. Flow cytometry performed on proliferative $\mathrm{MB}$ and on differentiating myocytes ( $\mathrm{MC}$ - harvested before the process of fusion) suggests that separate populations of DUOXA1 emerge (Figure 1D). Taken together, these results suggest that DUOXA1 is a highly dynamic protein whose levels and localization depend on whether samples are dividing or differentiating.

\section{DUOXA1 overexpression inhibits myogenesis}

In order to determine whether altering the levels of DUOXA1 might have an impact on myogenesis, we created an adenoviral vector containing full-length mouse DUOXA1 (pCMV5-DUOXA1-GFP). Virus containing the empty vector (pCMV5-GFP) was used as the corresponding control. Cells were infected, and induced to differentiate $24 \mathrm{hrs}$ later (designated as day 0 ). The efficiency of adenoviral infection in primary myoblasts was calculated to be $70-80 \%$ (data not shown). Quantitative RT-PCR at day 1 suggests that DUOXA1 overexpression reduced markers of early (myogenin) and late (myosin heavy chain - MyHC) differentiation by $66.4 \%$ and $69.1 \%$, respectively $(\mathrm{P}<0.05$, Figure $2 \mathrm{~A})$. Similarly, $M y o D$ mRNA was also reduced by $49.5 \%$ in cells overexpressing DUOXA1 ( $\mathrm{P}<0.05$, Figure $2 \mathrm{~A})$. Confocal immunofluorescence was performed on samples harvested at day
2 of differentiation. Although the numbers of $\mathrm{MyoD}^{+}$(red)/ $\mathrm{GFP}^{+}$(green) cells were not significantly different between samples (Figure 2B, $\mathrm{C}$ and $\mathrm{H}$ ), there was a $48.4 \%$ reduction in the number of myogenin ${ }^{+}(\mathrm{red}) / \mathrm{GFP}^{+}$(green) cells in DUOXA1 overexpressing samples compared to GFP cells $(\mathrm{P}<0.05$, Figure $2 \mathrm{D}, \mathrm{E}$ and $\mathrm{H})$. Similarly, immunostaining with an antibody against MyHC revealed a 29.8\% decrease in the number of $\mathrm{MyHC}^{+}$(red)/GFP (green) cells infected with DUOXA1, compared to GFP control samples $(\mathrm{P}<$ 0.05 , Figure $2 \mathrm{~F}, \mathrm{G}$ and $\mathrm{H}$ ). The ability of cells to fuse was also hindered in DUOXA1 overexpressing cells $(\mathrm{P}<0.05$, Figure 2I).

\section{DUOXA1 overexpression results in an increase in $\mathrm{H}_{2} \mathrm{O}_{2}$ production}

It has previously been determined that the translocation and maturation of DUOX1, and the subsequent production of $\mathrm{H}_{2} \mathrm{O}_{2}$, is dependent on the expression of DUOXA1 [8]. Having established the effects of DUOXA1 overexpression on myogenic differentiation, we questioned whether overexpression also resulted in alterations in the production of $\mathrm{H}_{2} \mathrm{O}_{2}$. Previous reports of DUOX1 expression in myoblasts had not been demonstrated, but we determined by immunostaining that DUOX1 was located primarily at the plasma membrane in these cells. We utilized an amplex red reagent to establish that DUOXA1 overexpressing cells indeed released more $\mathrm{H}_{2} \mathrm{O}_{2}$ into the surrounding medium than did GFP control cells. Overexpression resulted in a $59.3 \%$ increase in the levels of $\mathrm{H}_{2} \mathrm{O}_{2} \quad(\mathrm{P}<0.05$, Figure 2J). Hence, DUOXA1 overexpression resulted in elevated levels of $\mathrm{H}_{2} \mathrm{O}_{2}$, compromised fusion and inhibited differentiation.

\section{DUOXA1 overexpression elevates apoptosis signal-} regulating kinase (ASK) 1 expression and induces apoptosis in primary myoblasts undergoing differentiation

Within 48 hours of differentiation, DUOXA1 overexpressing cells appeared to be dying. Therefore, we assessed 


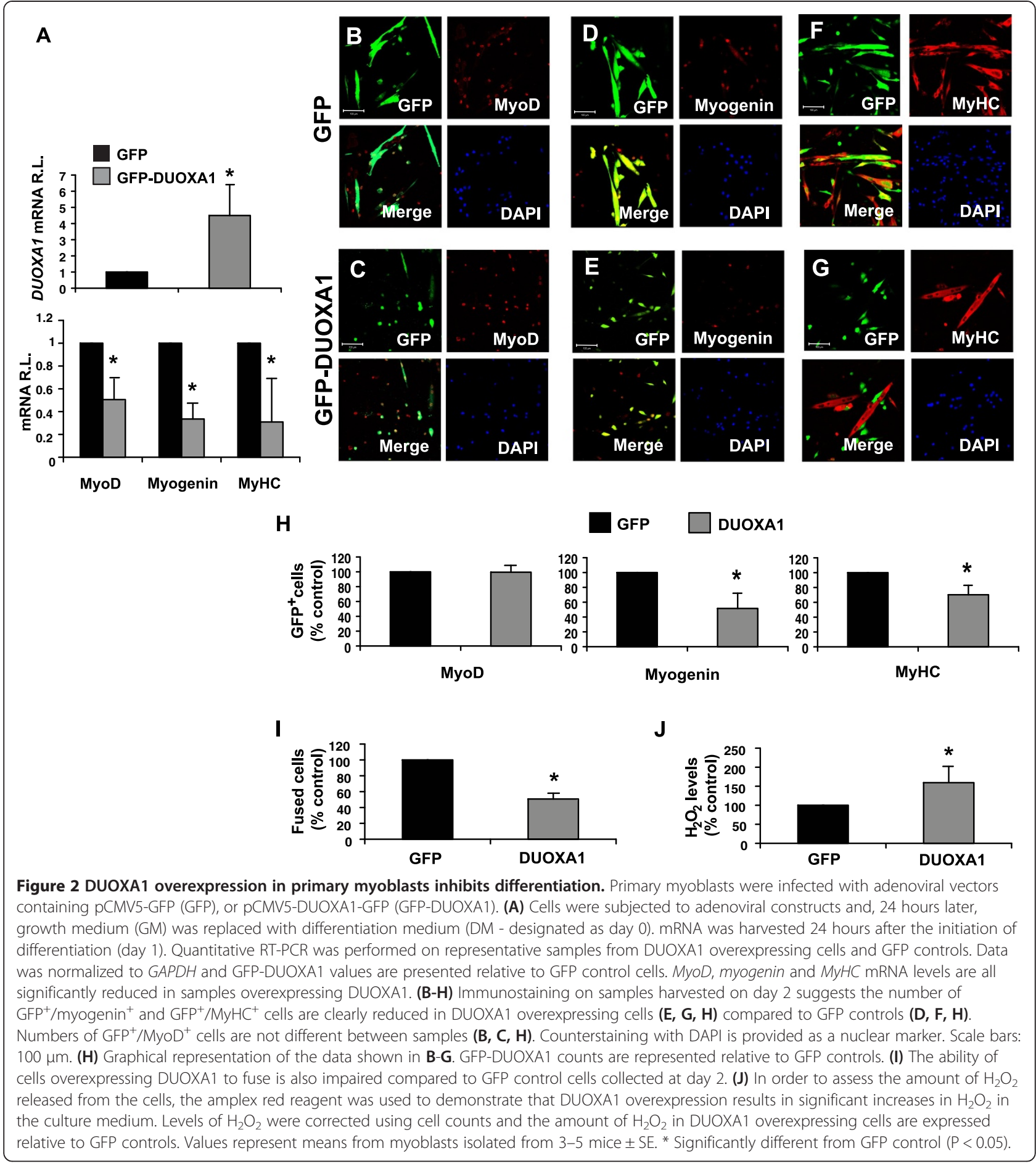

whether overexpression resulted in enhanced apoptosis during differentiation. We used AnnexinV-Cy3 and propridium iodide (TOPRO-3) to determine that, by day 1 of differentiation, DUOXA1 overexpression resulted in more than double the number of Annexin positive cells and over ten times the number of TOPRO-3 positive cells compared to GFP controls
$(\mathrm{P}<0.05$, Figure $3 \mathrm{~A}$ and $\mathrm{B})$, indicating significant increases in the number of cells undergoing early (Annexin positive) and late (Annexin, TOPRO-3 double positive) apoptosis. We next sought to determine whether enhanced apoptosis was associated with elevated levels of ASK1, a common mediator of apoptosis. Quantitative RT-PCR indicated that DUOXA1 

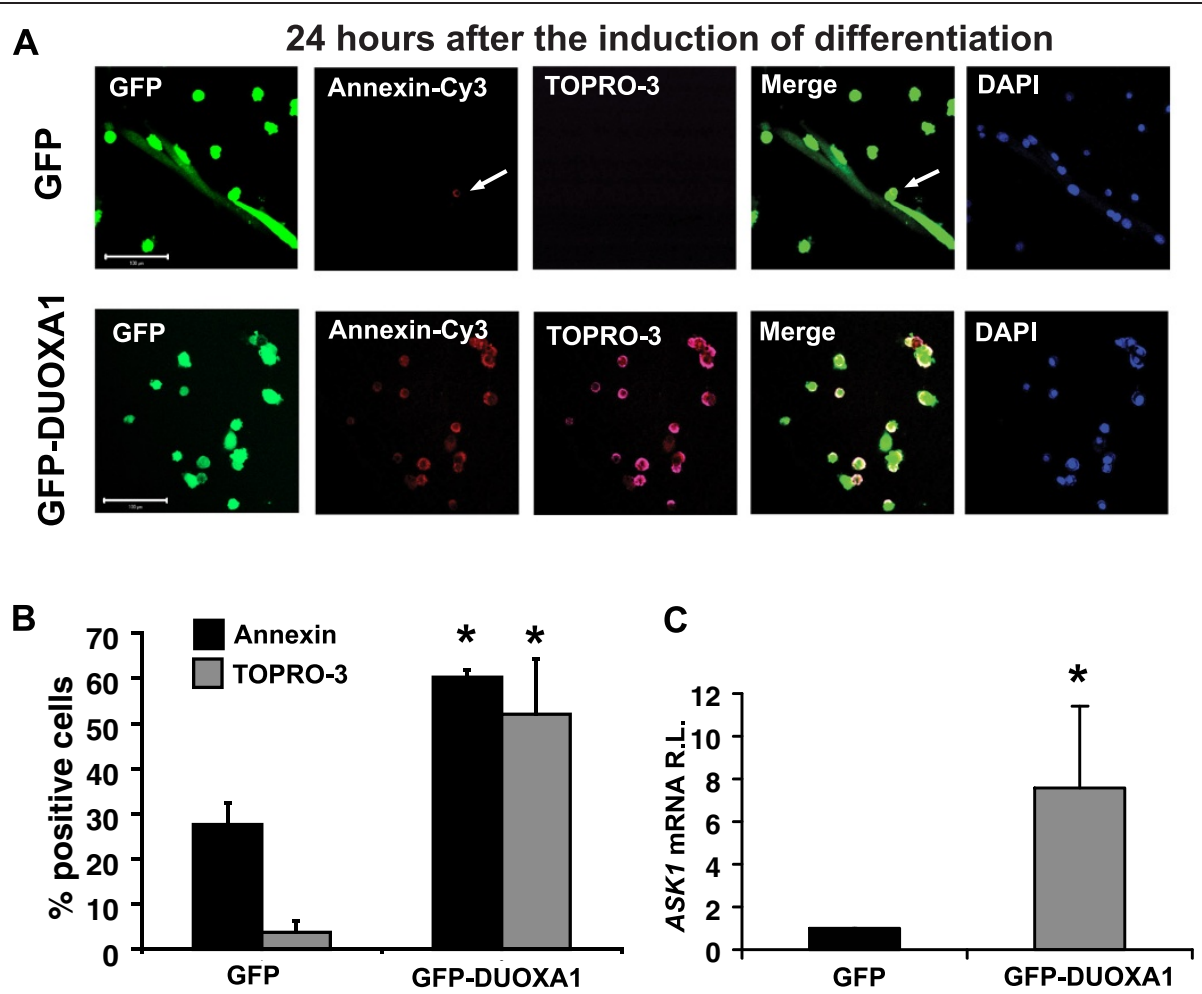

Figure 3 DUOXA1 overexpression elevates apoptosis signal-regulating kinase (ASK) 1 levels and induces apoptosis. (A-B) Cells were infected with pCMV5-GFP (GFP), or pCMV5-DUOXA1-GFP (GFP-DUOXA1). Twenty-four hours after infection, growth medium was replaced with differentiation medium and cells were harvested 24 hr later (day 1). (A) Apoptosis was measured by labelling samples with Annexin V-Cy3 (red) and propridium iodide (TOPRO-3 - magenta). Cells overexpressing DUOXA1 undergo massive amounts of apoptosis, as evidenced by cells undergoing early (Annexin $\mathrm{V}^{+} / \mathrm{TOPRO}^{-}{ }^{-}$) and late (Annexin $\mathrm{V}^{+} / \mathrm{TOPRO}^{+} 3^{+}$) apoptosis. Scale bars: $100 \mu \mathrm{m}$. (B) Graphical representation of data presented in (A). Counterstaining with DAPI is provided as a nuclear marker. (C) Levels of ASK1 in GFP and GFP-DUOXA1 samples were analyzed by qRT-PCR. Samples were normalized to GAPDH and GFP-DUOXA1 values are displayed relative to GFP controls. Data suggest upregulation of ASK1 in samples overexpressing DUOXA1. * Significantly different from GFP control $(P<0.05)$.

overexpressing samples had significantly elevated levels of ASK1 mRNA by five hours post infection $(\mathrm{P}<0.05$, Figure $3 C$ ).

\section{DUOXA1 knockdown results in enhanced differentiation} In order to further characterize a role for DUOXA1 in myogenesis, we used shRNA constructs targeting two separate regions of the DUOXA1 gene (DUOXA1 shRNA). A construct targeting luciferase was used as the corresponding control (CON shRNA). Data from one shRNA construct is depicted in Figure 4. DNA was introduced into the cells by nucleofection and, 24 hrs later, GM was replaced by DM. Samples were harvested on day 2. We demonstrated that DUOXA1 knockdown reduced DUOXA1 mRNA and protein using qRT-PCR, immunofluorescence and flow cytometry (Figure 4A and B). The amount of $\mathrm{H}_{2} \mathrm{O}_{2}$ released from the cells was also reduced by $31 \%(\mathrm{P}<0.05$, Figure $4 \mathrm{C})$. Quantitative RTPCR demonstrated that, while MyoD and $\mathrm{MyHC}$ were not differentially altered by DUOXA1 knockdown, there was a $58.7 \%$ increase in myogenin mRNA $(\mathrm{P}<0.05$, Figure 4D). Similarly, the number of Myogenin ${ }^{+}$cells was increased upon DUOXA1 knockdown $(\mathrm{P}<0.05$, Figure $4 \mathrm{E}-\mathrm{G})$. The number of $\mathrm{MyoD}^{+}$cells was not different between groups. Additionally, DUOXA1 knockdown resulted in a $91 \%$ increase in fusion $(\mathrm{P}<0.05$, Figure $4 \mathrm{H}$ ), and led to a $45 \%$ decrease in the number of cells undergoing apoptosis, as measured by AnnexinV staining $(\mathrm{P}<0.05$, Figure $4 \mathrm{I})$. Taken together, these data suggest that DUOXA1 knockdown reduces the levels of $\mathrm{H}_{2} \mathrm{O}_{2}$, enhances early markers of differentiation and the ability of cells to fuse.

The phenotype associated with DUOXA1 overexpression can be alleviated by DUOX1 or ASK1 depletion

The association between DUOXA1 and DUOX1 in other cell types is well established $[8,15,16,22]$. In order to determine whether the DUOXA1 phenotype was DUOX1 and/ or ASK1-dependent, we subjected primary myoblasts to siRNAs targeting DUOX1, ASK1 or a scrambled control by nucleofection. Twenty-four hours after nucleofection, samples were infected with adenoviral constructs containing GFP-DUOXA1 or a GFP control and, 24 hours later, differentiation was induced. Cells were harvested after 24 hours 


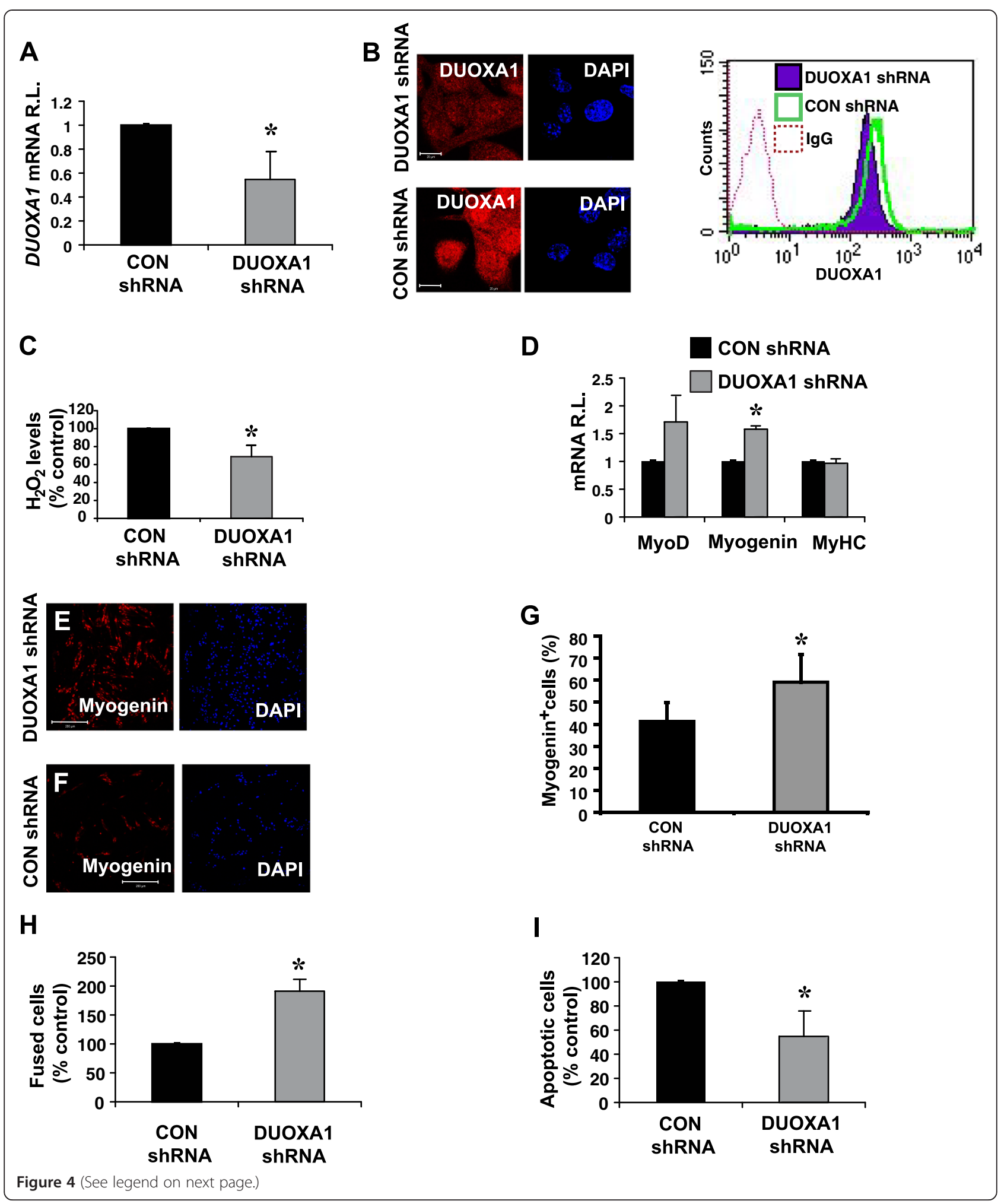




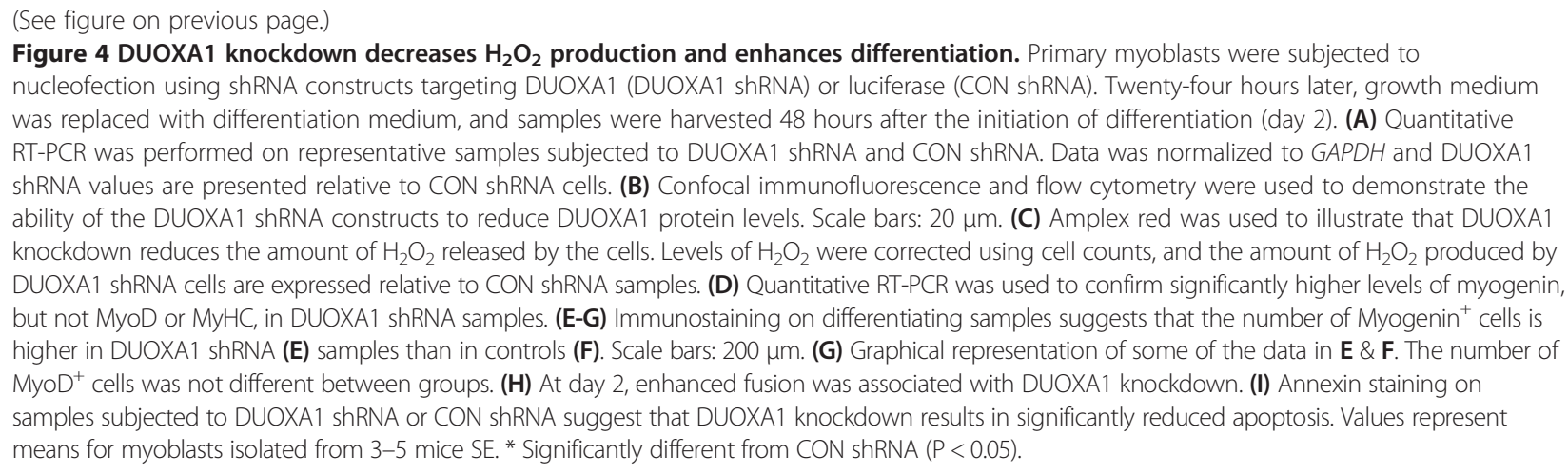

of differentiation. Samples subjected to both scrambled control siRNA and DUOXA1 overexpression demonstrated an $18.8 \%$ decrease in myogenin mRNA and a $37.9 \%$ decrease in $M y H C$ mRNA compared to control cells $(\mathrm{P}<0.05$, Figure $5 \mathrm{~A})$. Reductions in these two markers were alleviated by either DUOX1 knockdown or ASK1 knockdown. We used confocal microscopy and cell counts to determine that scrambled control siRNA cells overexpressing DUOXA1 experienced a $49.9 \%$ reduction in fusion $(\mathrm{P}<0.05)$ which was reversed with either DUOX1 siRNA or ASK1 siRNA (Figure 5B and C). Similarly, the $43.8 \%$ reduction in MyHC witnessed with DUOXA1 overexpression $(\mathrm{P}<0.05)$ was also alleviated upon knockdown of DUOX1 or ASK1 (Figure 5C). Levels of apoptosis common to DUOXA1 overexpression were also significantly lowered when these cells were subjected to DUOX1 or ASK1 depletion $(\mathrm{P}<0.05$, Figure $5 \mathrm{C})$. Although there was a similar trend for myogenin, levels of this marker were not significant. In order to determine whether DUOX1 and/or ASK1 knockdown altered the ability of the cells to differentiate, we subjected samples to either DUOX1 siRNA or ASK1 siRNA and CON siRNA. We determined that ASK1 knockdown on its own had no effect on differentiation, while DUOX1 knockdown increased the ability of the cells to fuse, but had no effect on the expression of Myogenin or MyHC (Figure 5D-F). Based on these findings, we propose a model whereby DUOXA1 overexpression hinders differentiation and initiates apoptosis through mechanisms involving DUOX1 and ASK1 (Figure 6).

\section{Discussion}

This report represents the first study to demonstrate the presence of a DUOX1-DUOXA1 system in activated satellite cells and primary myoblasts, and suggests an important role for DUOXA1 in normal myoblast function and differentiation. Our data imply that DUOXA1 levels and localization are altered as myoblasts differentiate, and that overexpression results in increased $\mathrm{H}_{2} \mathrm{O}_{2}$ production, apoptosis and defective differentiation. In agreement with our previous findings [22], we demonstrate that overexpression of DUOXA1 (and not the dual oxidase itself) can enhance $\mathrm{H}_{2} \mathrm{O}_{2}$ production in cells that already express DUOX1. The observation that endogenous DUOXA1 levels and localization change as cells differentiate is an interesting one. Flow cytometry data suggests that differentiation stimulates the emergence of two populations of cells with respect to DUOXA1 levels. The significance of these separate populations remains unclear. This pattern has been identified in other types of differentiating cells (data not shown) and suggests a level of caution be applied when analyzing DUOXA1 levels solely by Western blot.

The observation that adult skeletal muscle produces low amounts of ROS under resting conditions is well established, as is the importance of ROS in force development [23] and during myocyte disruption [24]. However, a potential role for endogenous ROS in myogenesis is poorly understood. Reactive oxygen species (ROS) are known to be important for the differentiation of cardiac [25-29], smooth muscle [30,31] and neuronal cells $[22,32,33]$. In skeletal muscle, it has been demonstrated that differentiation is naturally associated with elevated levels of ROS $[34,35]$ and, similar to other tissues, there are reports suggesting that a rise in ROS is necessary to support differentiation and fusion [34-36]. Nox family members Nox1, Nox 2 and Nox4 have been described in skeletal muscle and in myoblasts [19,35]. The ability of Nox proteins to mediate differentiation appears to be linked to ROS production, and the emerging picture is that proper control of development is tightly linked to ROS levels. Piao et al. [35] used siRNA against Nox1 and Nox2, and a range of inhibitors to determine that both knockdown of Nox 2 and the use of ROS scavengers inhibit myogenesis. Even though alterations in myoblast DUOXA1 levels produce an opposite phenotype to that observed for Nox2, it is interesting to note that the characterization of DUOXA1 and DUOX1 in myoblasts represents the fourth Nox system to be described in these cells. Differences in temporal expression during differentiation, and resulting phenotypes from 


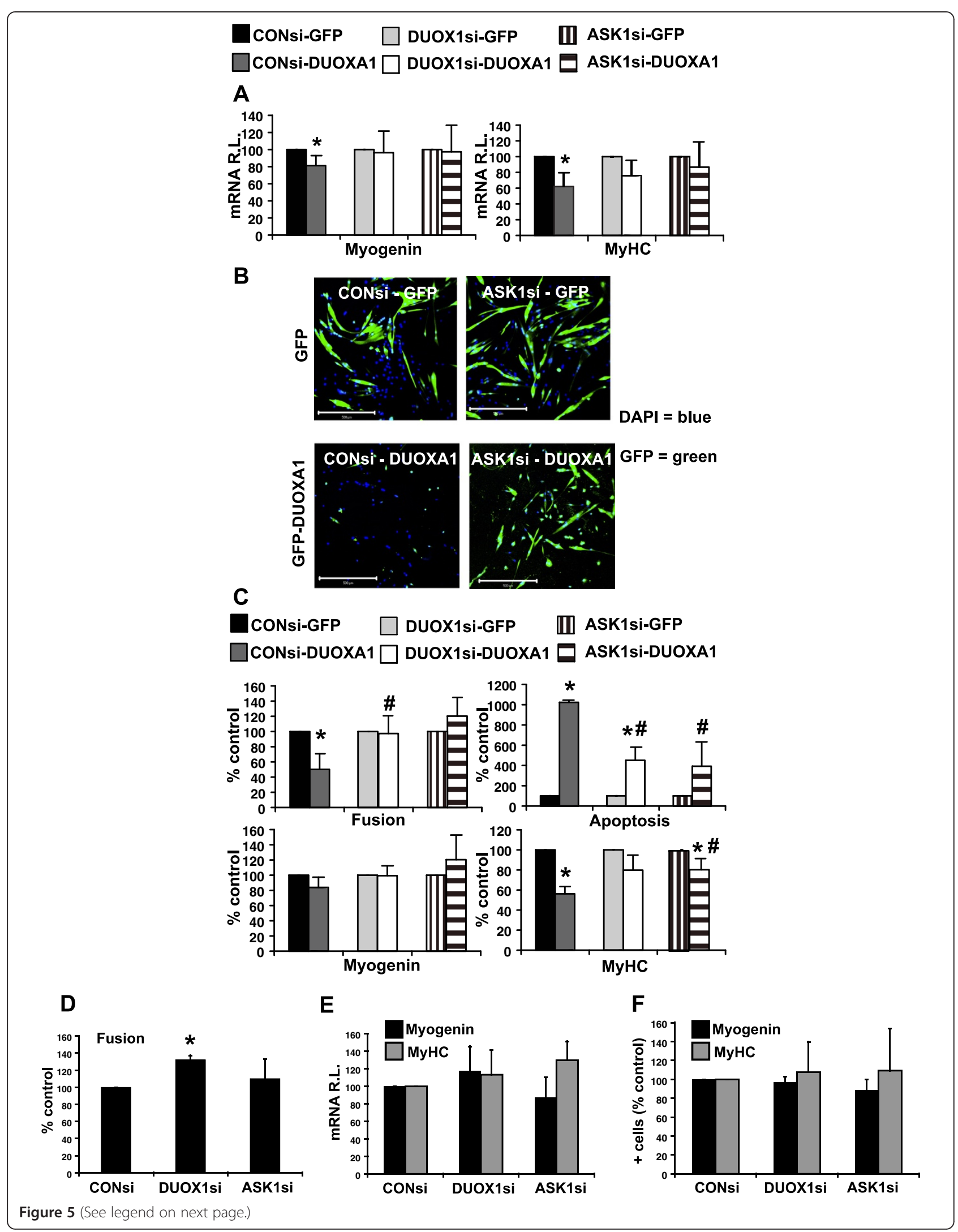


(See figure on previous page.)

Figure 5 DUOXA1 inhibits myogenesis through a mechanism involving DUOX1 and ASK1. Small interfering RNAs targeting DUOX1 (DUOX1 siRNA), ASK1 (ASK1 siRNA) or a scrambled control (CON siRNA) were introduced into myoblasts using nucleofection. After 24 hrs, samples were subjected to adenoviral vectors containing GFP-DUOXA1 (DUOXA1) or GFP. (A) Quantitative RT-PCR was performed on samples harvested on day 1. Data was normalized to GAPDH and DUOXA1 values are presented relative to corresponding GFP controls. Reductions in the levels of myogenin and MYHC mRNA associated with DUOXA1 overexpression are alleviated upon knockdown of DUOX1 or ASK1. (B) Images demonstrating the ability of ASK1 siRNA to rescue the DUOXA1 phenotype. GFP is visualized in samples. Scale bars: $500 \mu \mathrm{m}$. (C) Graphical representation of cell counts. Confocal immunofluorescence was performed on samples harvested at day 1, and the number of cells expressing Myogenin and MyHC were counted. The number of $\mathrm{MyHC}^{+}$cells was reduced in samples subjected to CON siRNA and DUOXA1 overexperssion compared to CON siRNA and GFP controls. This was alleviated by ASK1 knockdown. Counts are represented relative to their corresponding controls (e.g. DUOX1siDUOXA1 relative to DUOX1si-GFP). The large number of Annexin- $V^{+}$cells witnessed upon DUOXA1 overexpression and defects in cell fusion can be reversed with siRNAs targeting DUOX1 and/or ASK1. (D-F) To determine whether DUOX1 or ASK1 knockdown alone would have an effect on differentiation, we subjected samples to DUOX1 siRNA or ASK1 siRNA and a suitable control (CON siRNA). DUOX1 knockdown enhances fusion (D), but not Myogenin or MyHC mRNA (E) or protein levels (F). ASK1 knockdown had no effect on differentiation. *Significantly different from samples infected with the corresponding GFP control $(P<0.05$. \# Significantly different from samples nucleofected with a scrambled control (CON siRNA) and infected with a DUOXA1 construct (CONsi-DUOXA1, P $<0.05)$.

their knockdown or overexpression suggest that these enzymes may be activated by different stimuli, that they may signal through different pathways, and that they are likely not fully redundant.

It should also be noted that the immortalized $\mathrm{C} 2 \mathrm{C} 12$ myoblast cell line is the model of choice in many investigations. Work in our lab suggests that $\mathrm{C} 2 \mathrm{C} 12$ cells may be considerably more resistant to elevations in ROS levels than are primary myoblasts. Others have reported using $\mathrm{mM}$ levels of $\mathrm{H}_{2} \mathrm{O}_{2}$ to disrupt myogenesis. Although the exact level of $\mathrm{H}_{2} \mathrm{O}_{2}$ needed to induce catastrophic damage remains unclear, investigations confirming links between $\mathrm{ROS}$ and apoptosis in $\mathrm{C} 2 \mathrm{C} 12$ cells typically use
$0.5 \mathrm{mM}$ to $4 \mathrm{mM} \mathrm{H}_{2} \mathrm{O}_{2}$ [37-39]. Our preliminary data suggest that myogenesis can be inhibited using as little as 1-10 $\mu \mathrm{M} \mathrm{H}_{2} \mathrm{O}_{2}$ in primary myoblasts (S.D.E.S, unpublished data), with the ability of the cells to fuse being particularly susceptible. We thus decided to focus our studies on primary myoblasts since we assumed the data would be more relevant than that derived from immortalized cells. However, one of the challenges of working with primary cells is the small sample sizes. Since many of the conditions applied in this study also resulted in cell death, we made the decision to focus primarily on cell counts, qRT-PCR and, where applicable, flow cytometry. Immunoblotting was not possible under these conditions. However, the data

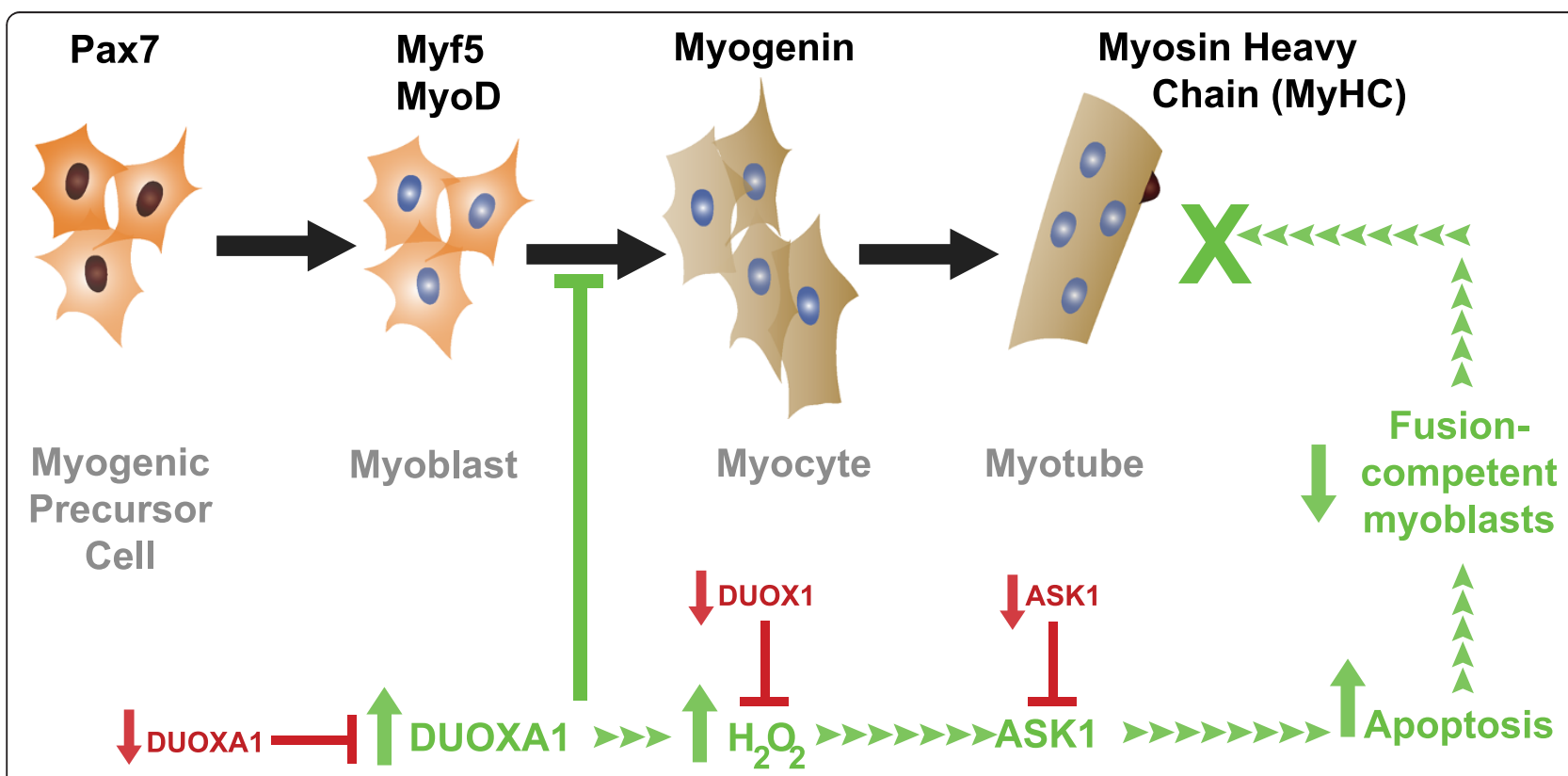

Figure 6 A model for the effects of DUOXA1 on muscle differentiation. The proposed model suggests that elevated levels of DUOXA1 act downstream of MyoD to initiate massive cell death and impair differentiation. DUOXA1 knockdown enhances differentiation. Samples subjected to siRNAs targeting DUOX1 or ASK1 rescues the overexpression phenotype. The effects of DUOXA1 overexpression and knockdown/rescue are presented in green and red, respectively, and suggest that DUOXA1-mediated apoptosis inhibits differentiation through a mechanism involving DUOX1 and ASK1. 
clearly demonstrate that high levels of DUOXA1 are detrimental to myogenesis and that its levels need to be strictly controlled. Future studies incorporating mouse and human primary cell models should begin to provide a clearer picture of the overall sensitivity of myoblasts to ROS and to provide a better understanding of how the Nox family of enzymes work to promote and inhibit myogenesis.

Proper skeletal muscle differentiation is dependent upon adequate pools of fusion-competent myoblasts. Apoptosis naturally occurs during differentiation, and there is some evidence to suggest that mediators of cell death are, in fact, required to initiate differentiation $[6,40]$. However, there appears to be some discrepancy between appropriate (and expected) levels of death associated with normal differentiation, and exaggerated levels of apoptosis resulting in severe reductions in cell numbers and hindered development. There are several reports indicating that controlling the level of apoptosis that occurs during differentiation may be therapeutically useful for a variety of degenerative diseases and aging [41-46].

Our results indicate that DUOXA1 overexpression can initiate the process of apoptosis through DUOX1 and ASK1. In our rescue experiments, DUOXA1 overexpression resulted in decreases in Myogenin mRNA but not protein. In other experiments (where levels of mRNA protein coincide with each other) cells were harvested after two days of differentiation. In our rescue experiments, samples were harvested after a single day of differentiation. This is due to the fact that the primary cells had been subjected to both adenovirus and nucleofection. Nucleofection is a very efficient method of gene transfer in primary myoblasts, but it also results in a small amount of toxicity. Since detectable differences in mRNA will always precede alterations in the level of protein, this earlier time point may have compromised our ability to detect larger differences in some of our parameters.

We discovered that ASK1 knockdown had no effect on differentiation. However, the observation that DUOX1 knockdown enhances the ability of the cells to fuse coincides with DUOXA1 data. It is curious that DUOX1 knockdown was not as effective as DUOXA1 at altering levels of Myogenin protein or RNA levels. While our data still suggests a connection between DUOXA1 and DUOX1 in the production of ROS and cell death in primary myoblasts, it is possible that DUOXA1 also has some DUOX1-independent role(s) that might also induce ROS production and/or cell death.

There are few papers focused on the effects of ASK1 on myogenesis. We chose this target since ASK1 has been previously shown to be activated by oxidative stress and it is known to lie upstream of both the JNK and p38 MAPK apoptotic pathways [47]. It was felt that this target would give us the most information, and serve as a starting point for future studies between DUOXA1 and apoptosis. A recent investigation by Han and coworkers [48] suggests that, apart from initiating cell death, p38 MAPK and JNK activation enhance myostatin expression. Myostatin is a negative regulator of skeletal muscle mass $[49,50]$. Since ASK1 lies upstream of both p38 MAPK and JNK, it follows that its stimulation might enhance myostatin expression and result in decreased myocyte fusion. Clear links between $\mathrm{H}_{2} \mathrm{O}_{2}$ and myostatin expression remain to be established, but a recent investigation determined that $\mathrm{C} 2 \mathrm{C} 12$ cells treated with myostatin produced higher levels of ROS than did controls [51]. Future studies might better determine the link between ROS, ASK1, myostatin and myogenesis.

Similarly, notch genes are also implicated in differentiation. Originally, our lab characterized DUOXA1 as a Numb-interacting protein. Drosophila NIP (dNIP) was observed to anchor Numb as a crescent to one side of the plasma membrane shortly before cell division, thus ensuring daughter cells to inherit different amounts of Numb and acquire distinct cell fates [7]. In an attempt to address the biological function of dNIP, we generated fly lines with either maternal deletion of nip or those expressing a UAS-nip-RNAi transgene. While nip deletion led to growth arrest and death at the $1^{\text {st }}$ larval instar, NIP-knockdown flies survived to adulthood. However, these flies exhibited defects in pre-adult development, displayed an inability to handle oxidative stress, and had a significantly reduced life span [52]. Intriguingly, these phenotypes could be fully rescued by ubiquitous expression of a UAS-nip or a UAS-nip ${ }^{N N / A A}$, the latter producing a NIP mutant bearing double Asn to Ala mutations, shown to be defective in Numb binding $[7,52]$. These results suggest that dNIP is essential for Drosophila development, but its in vivo function may not be related to Numb binding. We have also recently determined that mammalian DUOXA1 and Numb show differences in expression patterns in the developing brain, and that overexpression of DUOXA1 in P19 cells does not affect the regulation of Numb [22]. Thus, based on our recent findings in Drosophila, mouse brain and P19 cells, it is unlikely that interactions between DUOXA1 and Numb are functionally relevant.

\section{Conclusion}

This is the first report of DUOXA1 in satellite cells and primary myoblasts, and the results of our work suggest this protein (as has been demonstrated in the thyroid and lung) is partially responsible for ROS production in developing muscle and that tight control of its levels is necessary for optimal myogenesis. Despite the presence of DUOXA1 and DUOX1 in these cells throughout muscle development, our work suggests that their levels 
need to be strictly controlled. As outlined in Figure 6, our work demonstrates that constitutive overexpression of DUOXA1 induces apoptosis and inhibits differentiation through mechanisms involving DUOX1 and ASK1. However, it remains possible that DUOX1-independent mechanisms also contributed to the phenotype associated with overexpression. DUOXA1 is localized in both the cytoplasm and nucleus in dividing myoblasts, while DUOX1 appears to be restricted to the plasma membrane. This result is consistent with previous observations in which DUOXA1 is associated with internal membranes, but remains crucial for the maturation and/ or translocation of DUOX1 to the periphery of the cell [8]. The nuclear presence of DUOXA1 remains curious given its five transmembrane domains and welldocumented association with DUOX1. Our lab has recently performed extensive mass spectrometry analysis to identify alternate binding partners for DUOXA1 in both the cytoplasm and nucleus [22]. Future investigations might seek to determine whether this protein has DUOX1-independent roles and whether it might be upregulated in diseased or aging muscle to determine its potential value as a therapeutic agent.

\section{Materials and methods}

\section{Myofibre isolation and cell culture}

Adult CD57/BL6 mice ( $>6$ weeks of age) were used for myofibre and primary myoblast isolations. Mice were housed and bred in the Health Sciences Animal Care Facility at the University of Western Ontario, and all procedures were monitored under a protocol approved by the University of Western Ontario Council on Animal Care. Mice were killed by cervical dislocation and myofibres were isolated as previously described [53]. Briefly, extensor digitorum longus (EDL) muscles were dissected from the hindlimbs and digested in collagenase D (Roche Applied Science, Mississauga, ON, Canada) for one hour at $37^{\circ} \mathrm{C}$. Individual fibres were plated onto glass bottom dishes (MatTek corp, Ashland, MA) coated in $10 \%$ matrigel (BD Biosciences, San Jose, CA), and either fixed immediately in $2 \%$ paraformaldehyde (PFA) or cultured in plating medium for up to several days in Dulbecco's Minimum Essential Medium (DMEM, Sigma, St. Louis, MO), 10\% horse serum (HS, Gibco, Carlsbad, CA), $0.5 \%$ chick embryo extract (CEE, US Biologicals, Swampscott, MA) with streptomycin and penicillin (GIBCO) at $37^{\circ} \mathrm{C}$ in $5 \% \mathrm{CO}_{2}$. In order to determine whether satellite cells had entered into the cell cycle, myofibres were labelled with $10 \mu \mathrm{M}$ Bromodeoxy Uridine (BrdU, Sigma) at the time of plating and harvested after 24 hours in culture.

In order to generate primary myoblast cultures, myofibers were washed from the plates after three days of culture and the medium was switched to growth medium
(GM) containing DMEM, 10\% HS, 20\% fetal bovine serum (FBS, Biowest, Miami, FL), 1\% CEE, and $2.5 \mathrm{ng} / \mathrm{mL}$ basic fibroblast growth factor (bFGF, Promega, Madison, WI). Myoblasts were maintained in this medium for up to several days. As cells reached 50-70\% confluence, they were passaged after pre-plating for 15 minutes on matrigel coated dishes to remove fibroblasts, and plated on fresh matrigel coated dishes. The purity of the myoblast cultures was estimated by desmin staining to be $>95 \%$. In order to maintain the characteristics of the cells, all experiments were carried out on myoblasts that had undergone $4-7$ passages.

For experiments where cells were differentiated, cells were plated on matrigel coated dishes and grown until $50 \%$ confluent. At that time, GM was exchanged for differentiation medium (DM) containing DMEM, 2\% HS, $10 \%$ FBS, $0.5 \%$ CEE, and antibiotics. Cells were differentiated for 48 hours unless otherwise stated, harvested and analysed. At the time of harvest, primary myoblasts were fixed in 2\% PFA for 15 minutes and washed several times in phosphate buffered saline (PBS) and prepared for immunostaining.

\section{Adenoviral preparation}

All adenoviral and corresponding control vectors were obtained from MP Biomedicals (Montreal, QC). Fulllength mouse DUOXA1 was cloned into the BglII site of the CMV5-IRES-EGFP AdenoVator ${ }^{\mathrm{TM}}$ vector to create CMV5-DUOXA1-IRES-EGFP and sequencing was performed. The final adenoviral vector was created by homologous recombination of the aforementioned vector with AdEasy, and virus was generated and amplified in 293T cells. Viral purification was achieved using an Adeno-X Virus Purification Kit (Clontech, Mountain View, CA). CMV5-IRES-EGFP containing virus was used as the corresponding control.

\section{Viral infection}

Primary myoblasts were plated and maintained in growth medium until they reached $50-60 \%$ confluence. At this time, cultures were infected with either CMV5DUOXA1-IRES-EGFP or CMV5-IRES-EGFP containing viruses. Twenty-four hours after infection, GM was replaced with DM, and cells were harvested after 48 hours of differentiation, unless otherwise stated. Samples were harvested for mRNA, analyzed by microscopy or prepared for $\mathrm{H}_{2} \mathrm{O}_{2}$ determination.

\section{shRNA-mediated knockdown of DUOXA1 and siRNA-mediated knockdown of DUOX1 or ASK1}

Short hairpin RNA (shRNA) constructs targeting two separate regions of the DUOXA1 gene and a control construct targeting luciferase $(3 \mu \mathrm{g})$ were used in knockdown experiments. All DUOXA1 shRNA constructs and 
controls were purchased from OriGene (Rockville, MD). At the appropriate cell density, myoblasts $\left(6 \times 10^{5}\right.$ cells/ cuvette) were electroporated using an Amaxa Nucleofector unit and NHDF solution (Lonza, Walkerville, MD). Twenty-four hours after nucleofection, GM was replaced with DM, and cells were harvested after 48 hours of differentiation. Samples were harvested for mRNA, analyzed by microscopy or prepared for $\mathrm{H}_{2} \mathrm{O}_{2}$ determination. In order to determine whether knocking down DUOX1 or ASK1 might rescue the phenotype corresponding to DUOXA1 overexpression, siRNA constructs targeting DUOX1, ASK1 or a scrambled control were purchased from Santa Cruz (Santa Cruz, CA). Small interfering RNA was introduced into proliferative primary myoblasts using nucleofection described above. Twenty four hours after nucleofection, samples were infected with adenoviral vectors containing GFP-DUOXA1 or GFP alone. Differentiation was initiated 24 hours after infection and samples were harvested 24 or 48 hours later. Sequences used in the preparation of siRNA and shRNA are presented in Additional file 2: Table S1.

\section{Immunostaining}

Myofibres and myoblasts were permeabilized in 0.5\% and $0.2 \%$ triton-X 100, respectively. After blocking for one hour in $1 \%$ bovine serum albumin (BSA), samples were incubated overnight at $4^{\circ} \mathrm{C}$ in a solution containing antibodies against MyoD (1:50), myogenin (1:50, Abcam, Cambridge, MA), BrdU (1:1500), myosin heavy chain (neat) (Developmental Studies Hybridoma Bank, Iowa), desmin (1:200, Molecular Probes, Eugene, OR), and DUOX1 (1:30, Santa Cruz, Santa Cruz, CA). For DUOXA1 detection, an antibody was generated in our lab against the C-terminal portion of the protein (CFKEEHPKESD) and validated against a blocking peptide [22]. Anti-DUOXA1 was used at a dilution of 1:300. Samples were washed and visualized with AlexaFluor secondary antibodies diluted 1:1000 (Molecular Probes). 4'6-diamidino-2-phenylindole (DAPI, Sigma) was used as a nuclear marker. Confocal microscopy was performed on a Zeiss LSM 510 META confocal microscope (Carl Zeiss, Germany) using $20 \times$, $40 \times$ or $63 \times$ objectives. Images were collected using Laser Scanning Microscope (LSM) software and optimized using PhotoImpression5 software.

\section{Apoptosis assays}

Apoptotic cells were identified using an Annexin V-Cy3 kit according to the manufacturer's instructions (BioVision, Mountain View, CA). Briefly, live cells were incubated in binding buffer supplied with the kit, along with Annexin V-Cy3 (1:100), propridium iodide (TOPRO-3, 1:1000) and Hoechst 33342 (1:2000, Molecular Probes). Samples were maintained in a heating block set to $37^{\circ} \mathrm{C}$ during analysis, and cells undergoing early (Annexin $\mathrm{V}^{+}$/TOPRO-3 $3^{-}$) or late (Annexin $\mathrm{V}^{+} /$TOPRO- $3^{+}$) apoptosis were compared with the total number of cells (identified with Hoechst dye). In overexpression experiments where GFP could be used as a marker, only $\mathrm{GFP}^{+}$cells were included in the analysis. Hoechst dye, GFP, Annexin V-Cy3 and TOPRO-3 were visualized using a Zeiss LSM 510 META confocal microscope, with excitation lasers set to $405 \mathrm{~nm}, 488 \mathrm{~nm}$, $543 \mathrm{~nm}$ and $633 \mathrm{~nm}$, respectively.

\section{RNA extraction, CDNA synthesis and quantitative reverse transcription (qRT)-PCR}

Total RNA was extracted from samples using TRIzol reagent, according to the manufacturer's instructions (Invitrogen, Burlington, ON). First-strand cDNA was generated from 100 to 300 ng RNA using the QuantiTect Reverse Transcription kit (Qiagen, Toronto, ON), which provides an initial step to eliminate genomic DNA. The samples were diluted and 1/15 of this mixture was quantified in subsequent PCR reactions using PerfeCTa SYBR Green SuperMix (Quanta Biosciences, Gaithersburg, MD). Samples were analyzed using the Rotor-Gene Q (Qiagen, Toronto, ON) and the corresponding software. Relative gene expression was calculated using the $\mathrm{Ct}$ method, and all samples were normalized to glyceraldyhyde-3-phosphate dehydrogenase (GAPDH). All averages \pm S.D. are displayed as fold changes relative to gene levels at $\mathrm{d} 0$ or to GFP control cells, depending on the experiment. Primer pairs were derived from the PrimerBank (http://pga.mgh.harvard. edu/primerbank/), or from previous publications, and are listed in Additional file 3: Table S2.

\section{Measurement of $\mathrm{H}_{2} \mathrm{O}_{2}$ using Amplex Red}

Hydrogen peroxide production was determined using an Amplex Red kit (Molecular Probes), according to the manufacturer's instructions. In the presence of peroxidase, Amplex Red reagent reacts with $\mathrm{H}_{2} \mathrm{O}_{2}$ (in 1:1 stoichiometry) to produce a red fluorescent product called resoruffin. The high extinction coefficient of resoruffin allows for analysis either fluorometrically or spectrophotometrically. Aliquots of medium were subsequently removed and analyzed spectrophotometrically at a wavelength of $560 \mathrm{~nm}$. After $\mathrm{H}_{2} \mathrm{O}_{2}$ determination, samples were washed thoroughly and corrected for cell number using a CytoSelect colormetric assay kit (Cell Biolabs, Inc., San Diego, CA). Dye from the stained cells was extracted and quantified at OD $560 \mathrm{~nm}$.

\section{Statistical analysis}

Where primary myoblasts were quantified by microscopy for a given antigen, cells from at least 10 random fields were counted and scored. Primary myoblasts from 
at least three mice were analysed. Images were optimized and assembled into figures using Adobe Illustrator. In order to determine the fusion index, the number of structures containing 2 or more nuclei were analysed from at least three separate mice. The fusion index was calculated as:

$$
\begin{aligned}
& \text { (\# of fused cells containing at least } 2 \text { nuclei/total \# } \\
& \text { of cells) } x 100
\end{aligned}
$$

In overexpression experiments (where GFP was available as a marker), $\mathrm{GFP}^{+}$cells were counted for quantification and fusion was calculated as:

$$
\begin{aligned}
& \text { (\# of fused } G F P^{+} \text {cells containing at least } 2 \text { nuclei/ } \\
& \text { total \# of } G F P^{+} \text {cells) } x 100
\end{aligned}
$$

$\mathrm{P}<0.05$ was considered significantly different between conditions, and was calculated using a Student's $t$-test.

\section{Additional files}

Additional file 1: Figure S1. (A) In order to determine the specificity of a lab-derived anti-DUOXA1 antibody, Western blotting was performed on 293 T cell samples transfected with either DUOXA1 or the corresponding empty vector (CON). (B) Since DUOXA1 is known to be glycosylated [16], we subjected $293 \mathrm{~T}$ cell lysates overexpressing DUOXA1 to N-glycosidase-F for $2 \mathrm{hr}$ at $37^{\circ} \mathrm{C}$. Results demonstrate that deglycosylation results in the DUOXA1 band migrating to its predicted weight of $37 \mathrm{kDa}$. (C-D) Immunostaining was on primary mouse myoblasts. Samples were incubated overnight with a rabbit anti-DUOXA1 antibody either in the absence (C), or presence (D) of a blocking peptide (BP), and visualized with an Alexa 488 conjugated secondary antibody. Scale bars: $50 \mu \mathrm{m}$. Inset scale bars: $10 \mu \mathrm{m}$. (E) Further support was derived from adenoviral infection of the immortalized C2C12 myoblast cell line. Cells successfully infected with GFP-DUOXA1 show bright green fluorescence (green) along with bright DUOXA1 staining (red) indicating substantial overexpression of DUOXA1. GFP control cells do not demonstrate elevated levels of DUOXA1. Scale bars: $20 \mu \mathrm{m}$.

Additional file 2: Table S1. Sequences used for siRNA and shRNA construction

Additional file 3: Table S2. Primers used for qRT-PCR.

\section{Abbreviations}

NIP: Numb interacting protein; DUOX: Dual oxidase; DUOXA1: Dual oxidase maturation factor 1; ROS: Reactive oxygen species; ASK1: Apoptosis signal-regulating kinase 1; BrdU: Bromo-deoxy uridine; GM: Growth medium; DM: Differentiation medium; shRNA: Short hairpin RNA; siRNA: small interfering RNA; qRT: quantitative reverse transcription.

\section{Competing interests}

The authors declare that they have no competing interests.

\section{Authors' contributions}

SS designed, performed and analyzed experiments and wrote the manuscript. KK analyzed RNA samples. XX designed the peptide which was used to produce the DUOXA1 primary antibody. JGP contributed to the gene transfer studies and helped draft the manuscript. SL supervised the experiments and helped draft the manuscript. All authors read and approved the final manuscript.

\section{Acknowledgements}

We thank Drs. Siu Pok Yee and Jack Hu for helpful discussions. We also thank Caroline O'Neil and members of Dr. John McCormick's laboratory for their technical assistance. This work was supported by grants to SSCL from the
Heart and Stroke Foundation of Ontario and the Natural Sciences and Engineering Research Council of Canada. JGP holds the Heart and Stroke Foundation of Ontario/Barnett-Ivey Chair. SSCL holds a Canada Research Chair in Functional Genomics and Cellular Proteomics.

\section{Author details}

${ }^{1}$ Siebens-Drake Research Institute, 1400 Western Road, London, Ontario N6G $2 \mathrm{~V} 4$, Canada. ${ }^{2}$ Department of Biochemistry and the Siebens-Drake Medical Research Institute, Schulich School of Medicine and Dentistry, Western University, London, Ontario N6A 5C1, Canada.

Received: 15 July 2013 Accepted: 23 December 2013

Published: 11 January 2014

\section{References}

1. Mauro A: Satellite cell of skeletal muscle fibers. J Biophys Biochem Cytol 1961, 9:493-495.

2. Tajbakhsh S, Buckingham M: The birth of muscle progenitor cells in the mouse: spatiotemporal considerations. Curr Top Dev Biol 2000, 48:225-268.

3. Kassar-Duchossoy L, Gayraud-Morel B, Gomès D, Rocancourt D, Buckingham $M$, Shinin V, Tajbakhsh S: Mrf4 determines skeletal muscle identity in Myf5:Myod double-mutant mice. Nature 2004, 431:466-471.

4. Zammit PS, Golding JP, Nagata Y, Hudon V, Partridge TA, Beauchamp JR: Muscle satellite cells adopt divergent fates: a mechanism for self-renewal? J Cell Biol 2004, 166:347-357.

5. Dee K, Freer M, Mei Y, Weyman CM: Apoptosis coincident with the differentiation of skeletal myoblasts is delayed by caspase 3 inhibition and abrogated by MEK-independent constitutive Ras signaling. Cell Death Differ 2002, 9:209-218.

6. Nakanishi K, Sudo T, Morishima N: Endoplasmic reticulum stress signaling transmitted by ATF6 mediates apoptosis during muscle development. J Cell Biol 2005, 169:555-560.

7. Qin H, Percival-Smith A, Li C, Jia CYH, Gloor G, Li SS-C: A novel transmembrane protein recruits numb to the plasma membrane during asymmetric cell division. J Biol Chem 2004, 279:11304-11312.

8. Grasberger H, Refetoff S: Identification of the maturation factor for dual oxidase. Evolution of an eukaryotic operon equivalent. J Biol Chem 2006 281:18269-18272.

9. Bedard K, Krause K-H: The NOX family of ROS-generating NADPH oxidases: physiology and pathophysiology. Physiol Rev 2007, 87:245-313.

10. Donkó A, Péterfi Z, Sum A, Leto T, Geiszt M: Dual oxidases. Philos Trans $R$ Soc Lond B Biol Sci 2005, 360:2301-2308.

11. Geiszt M: NADPH oxidases: new kids on the block. Cardiovasc Res 2006, 71:289-299.

12. Sumimoto H: Structure, regulation and evolution of Nox-family NADPH oxidases that produce reactive oxygen species. FEBS $J 2008$, 275:3249-3277.

13. Ameziane-El-Hassani R, Morand S, Boucher J-L, Frapart Y-M, Apostolou D, Agnandji D, Gnidehou S, Ohayon R, Noël-Hudson M-S, Francon J, Lalaoui K, Virion A, Dupuy C: Dual Oxidase-2 Has an Intrinsic Ca2 +-dependent H2O2-generating Activity. J Biol Chem 2005, 280:30046-30054.

14. Wang D, De Deken X, Milenkovic M, Song Y, Pirson I, Dumont JE, Miot F: Identification of a novel partner of duox: EFP1, a thioredoxin-related protein. J Biol Chem 2005, 280:3096-3103.

15. Luxen S, Noack D, Frausto M, Davanture S, Torbett BE, Knaus UG: Heterodimerization controls localization of Duox-DuoxA NADPH oxidases in airway cells. J Cell Sci 2009, 122(Pt 8):1238-1247.

16. Morand S, Ueyama T, Tsujibe S, Saito N, Korzeniowska A, Leto TL: Duox maturation factors form cell surface complexes with Duox affecting the specificity of reactive oxygen species generation. FASEB J 2009, 23:1205-1218

17. Grasberger H, De Deken X, Miot F, Pohlenz J, Refetoff S: Missense mutations of dual oxidase 2 (DUOX2) implicated in congenital hypothyroidism have impaired trafficking in cells reconstituted with DUOX2 maturation factor. Mol Endocrinol 2007, 21:1408-1421.

18. Zamproni I, Grasberger H, Cortinovis F, Vigone MC, Chiumello G, Mora S Onigata K, Fugazzola L, Refetoff S, Persani L, Weber G: Biallelic inactivation of the dual oxidase maturation factor 2 (DUOXA2) gene as a novel cause of congenital hypothyroidism. J Clin Endocrinol Metab 2008, 93:605-610.

19. Krause $\mathrm{K}-\mathrm{H}$ : Tissue distribution and putative physiological function of NOX family NADPH oxidases. Jpn J Infect Dis 2004, 57:S28-S29. 
20. Gattas MV, Forteza R, Fragoso MA, Fregien N, Salas P, Salathe M, Conner GE: Oxidative epithelial host defense is regulated by infectious and inflammatory stimuli. Free Radic Biol Med 2009, 47:1450-1458.

21. Luxen S, Belinsky SA, Knaus UG: Silencing of DUOX NADPH oxidases by promoter hypermethylation in lung cancer. Cancer Res 2008, 68:1037-1045.

22. Kennedy KAM, Ostrakhovitch EA, Sandiford SDE, Dayarathna T, Xie X, Waese EYL, Chang WY, Feng Q, Skerjanc IS, Stanford WL, Li SSC: Mammalian numb-interacting protein 1/dual oxidase maturation factor 1 directs neuronal fate in stem cells. J Biol Chem 2010, 285:17974-17985.

23. Lecarpentier $Y$ : Physiological role of free radicals in skeletal muscles. J Appl Physiol 2007, 103:1917-1918.

24. Kerkweg U, Petrat F, Korth $\mathrm{H}-\mathrm{G}$, de Groot $\mathrm{H}$ : Disruption of skeletal myocytes initiates superoxide release: contribution of NADPH oxidase. Shock 2007, 27:552-558.

25. Buggisch M, Ateghang B, Ruhe C, Strobel C, Lange S, Wartenberg M, Sauer $\mathrm{H}$ : Stimulation of ES-cell-derived cardiomyogenesis and neonatal cardiac cell proliferation by reactive oxygen species and NADPH oxidase. J Cell Sci 2007, 120(Pt 5):885-894.

26. Haneline LS: Redox regulation of stem and progenitor cells. Antioxid Redox Signal 2008, 10:1849-1852.

27. Li J, Stouffs M, Serrander L, Banfi B, Bettiol E, Charnay Y, Steger K, Krause $\mathrm{K}-\mathrm{H}$, Jaconi ME: The NADPH oxidase NOX4 drives cardiac differentiation: Role in regulating cardiac transcription factors and MAP kinase activation. Mol Biol Cell 2006, 17:3978-3988.

28. Sauer $H$, Wartenberg M: Reactive oxygen species as signaling molecules in cardiovascular differentiation of embryonic stem cells and tumor-induced angiogenesis. Antioxid Redox Signal 2005, 7:1423-1434.

29. Sauer H, Rahimi G, Hescheler J, Wartenberg M: Effects of electrical fields on cardiomyocyte differentiation of embryonic stem cells. J Cell Biochem 1999, 75:710-723.

30. Pepe AE, Xiao Q, Zampetaki A, Zhang Z, Kobayashi A, Hu Y, Xu Q: Crucial role of nrf3 in smooth muscle cell differentiation from stem cells. Circ Res 2010, 106:870-879

31. Xiao Q, Luo Z, Pepe AE, Margariti A, Zeng L, Xu Q: Embryonic stem cel differentiation into smooth muscle cells is mediated by Nox4-produced H2O2. Am J Physiol Cell Physiol 2009, 296:C711-C723.

32. Kennedy KAM, Sandiford SDE, Skerjanc IS, Li SS-C: Reactive oxygen species and the neuronal fate. Cell Mol Life Sci 2011, 69:215-221.

33. Le Belle JE, Orozco NM, Paucar AA, Saxe JP, Mottahedeh J, Pyle AD, Wu H, Kornblum HI: Proliferative neural stem cells have high endogenous ROS levels that regulate self-renewal and neurogenesis in a PI3K/Akt-dependant manner. Cell Stem Cell 2011, 8:59-71.

34. Lee S, Tak E, Lee J, Rashid MA, Murphy MP, Ha J, Kim SS: Mitochondrial $\mathrm{H} 2 \mathrm{O} 2$ generated from electron transport chain complex I stimulates muscle differentiation. Cell Res 2011, 21:817-834.

35. Piao YJ, Seo YH, Hong F, Kim JH, Kim Y-J, Kang MH, Kim BS, Jo SA, Jo I, Jue D-M, Kang I, Ha J, Kim SS: Nox 2 stimulates muscle differentiation via NF-kappaB/iNOS pathway. Free Radic Biol Med 2005, 38:989-1001.

36. Handayaningsih A-E, Iguchi G, Fukuoka H, Nishizawa H, Takahashi M, Yamamoto M, Herningtyas E-H, Okimura Y, Kaji H, Chihara K, Seino S, Takahashi Y: Reactive oxygen species play an essential role in IGF-I signaling and IGF---induced myocyte hypertrophy in C2C12 myocytes. Endocrinology 2011, 152:912-921.

37. Furutani $Y$, Murakami M, Funaba M: Differential responses to oxidative stress and calcium influx on expression of the transforming growth factor-beta family in myoblasts and myotubes. Cell Biochem Funct 2009, 27:578-582.

38. Salucci S, Battistelli M, Burattini S, Squillace C, Canonico B, Gobbi P, Papa S, Falcieri E: C2C12 myoblast sensitivity to different apoptotic chemical triggers. Micron 2010, 41:966-973.

39. Siu PM, Wang Y, Alway SE: Apoptotic signaling induced by $\mathrm{H} 2 \mathrm{O} 2$-mediated oxidative stress in differentiated C2C12 myotubes. Life Sci 2009, 84:468-481.

40. Fernando P, Kelly JF, Balazsi K, Slack RS, Megeney LA: Caspase 3 activity is required for skeletal muscle differentiation. Proc Natl Acad Sci U S A 2002, 99:11025-11030.

41. Ciavarra G, Ho AT, Cobrinik D, Zacksenhaus E: Critical role of the Rb family in myoblast survival and fusion. PLOS ONE 2011, 6:e17682

42. Deponti D, François S, Baesso S, Sciorati C, Innocenzi A, Broccoli V, Muscatelli F, Meneveri R, Clementi E, Cossu G, Brunelli S: Necdin mediates skeletal muscle regeneration by promoting myoblast survival and differentiation. J Cell Biol 2007, 179:305-319.
43. Giampietri C, Petrungaro S, Coluccia P, Antonangeli F, Giannakakis K, Faraggiana T, Filippini A, Cossu G, Ziparo E: c-Flip overexpression affects satellite cell proliferation and promotes skeletal muscle aging. Cell Death Dis 2010, 1:e38.

44. Jansen KM, Pavlath GK: Prostaglandin F2alpha promotes muscle cell survival and growth through upregulation of the inhibitor of apoptosis protein BRUCE. Cell Death Differ 2008, 15:1619-1628.

45. Marzetti E, Calvani R, Bernabei R, Leeuwenburgh C: Apoptosis in skeletal myocytes: a potential target for interventions against sarcopenia and physical frailty - a mini-review. Gerontology 2011, 58:99-106.

46. Miyake M, Hayashi S, Iwasaki S, Uchida T, Watanabe K, Ohwada S, Aso H, Yamaguchi T: TIEG1 negatively controls the myoblast pool indispensable for fusion during myogenic differentiation of $\mathrm{C} 2 \mathrm{C} 12$ cells. J Cell Physiol 2011, 226:1128-1136.

47. Katagiri K, Matsuzawa A, Ichijo H: Chapter 16 - Regulation of apoptosis signal-regulating kinase 1 in redox signaling. In Methods in Enzymology. 474th edition. Edited by Cadenas E, Packer L. Waltham, Massachusetts, USA: Academic Press; 2010:277. Thiol Redox Transitions in Cell Signaling, Part B: Cellular Localization and Signaling.

48. Han D-S, Huang H-P, Wang T-G, Hung M-Y, Ke J-Y, Chang K-T, Chang H-Y, Ho Y-P, Hsieh W-Y, Yang W-S: Transcription activation of myostatin by trichostatin $\mathrm{A}$ in differentiated $\mathrm{C} 2 \mathrm{C} 12$ myocytes via ASK1-MKK3/4/6-JNK and p38 mitogen-activated protein kinase pathways. J Cell Biochem 2010, 111:564-573.

49. Lee SJ, McPherron AC: Myostatin and the control of skeletal muscle mass. Curr Opin Genet Dev 1999, 9:604-607.

50. McPherron AC, Lawler AM, Lee SJ: Regulation of skeletal muscle mass in mice by a new TGF-beta superfamily member. Nature 1997, 387:83-90.

51. Sriram S, Subramanian S, Sathiakumar D, Venkatesh R, Salerno MS, McFarlane CD, Kambadur R, Sharma M: Modulation of reactive oxygen species in skeletal muscle by myostatin is mediated through NF-KB. Aging Cell 2011, 10:931-948.

52. Xie X, Hu J, Liu X, Qin H, Percival-Smith A, Rao Y, Li SSC: NIP/DuoxA is essential for Drosophila embryonic development and regulates oxidative stress response. Int J Biol Sci 2010, 6:252-267.

53. Rosenblatt JD, Lunt Al, Parry DJ, Partridge TA: Culturing satellite cells from living single muscle fiber explants. In Vitro Cell Dev Biol Anim 1995, 31:773-779.

doi:10.1186/1478-811X-12-5

Cite this article as: Sandiford et al:: Dual Oxidase Maturation factor 1 (DUOXA1) overexpression increases reactive oxygen species production and inhibits murine muscle satellite cell differentiation. Cell Communication and Signaling 2014 12:5.

\section{Submit your next manuscript to BioMed Central and take full advantage of:}

- Convenient online submission

- Thorough peer review

- No space constraints or color figure charges

- Immediate publication on acceptance

- Inclusion in PubMed, CAS, Scopus and Google Scholar

- Research which is freely available for redistribution 